\title{
Modeling and Backstepping Control of the Electronic Throttle System
}

\author{
Rui Bai, ${ }^{1}$ Shaocheng Tong, ${ }^{1}$ and Hamid Reza Karimi ${ }^{2}$ \\ ${ }^{1}$ School of Electrical Engineering, Liaoning University of Technology, Jinzhou 121001, China \\ ${ }^{2}$ Department of Engineering, Faculty of Engineering and Science, University of Agder, 4898 Grimstad, Norway
}

Correspondence should be addressed to Rui Bai; broffice@126.com

Received 20 August 2013; Accepted 22 September 2013

Academic Editor: Tao Li

Copyright (c) 2013 Rui Bai et al. This is an open access article distributed under the Creative Commons Attribution License, which permits unrestricted use, distribution, and reproduction in any medium, provided the original work is properly cited.

\begin{abstract}
Electronic throttle is widely used in modern automotive engines. An electronic throttle system regulates the throttle plate angle by using a DC servo motor to adjust the inlet airflow rate of an internal combustion engine. Its application leads to improvements in vehicle drivability, fuel economy, and emissions. In this paper, by taking into account the dynamical behavior of the electronic throttle, the mechanism model is first built, and then the mechanism model is transformed into the state-space model. Based on the state-space model and using the backstepping design technique, a new backstepping controller is developed for the electronic throttle. The proposed controller can make the actual angle of the electronic throttle track its set point with the satisfactory performance. Finally, a computer simulation is performed, and simulation results verify that the proposed control system can achieve favorable tracking performance.
\end{abstract}

\section{Introduction}

In recent years, many functions of modern automobiles are shifting from a purely mechanical to an electromechanical implementation. These functions are implemented by using the so-called "x-by-wire" systems, including drive-by-wire and steer-by-wire systems [1]. "X-by-wire" systems act as an interface between the driver and the targeted mechanical subsystem of the vehicle. Now, advanced control strategies, including the data-driven control [2], fuzzy control [3,4], and neural network control $[5,6]$, have been widely applied in the process industry and automobile industry, for example, the Tennessee Eastman process [7], the suspension control system $[8,9]$, the electronic throttle control system $[10,11]$, and so on. In this paper, we focus on the control strategy of the electronic throttle system, which is one of the important drive-by-wire systems in the automobile industry.

In automotive spark ignition engines, the air coming into the intake manifold and therefore the power generated strongly depend on the angular position of a throttle valve [12]. In traditional systems, the throttle position is actuated by a mechanical link with the accelerator pedal, directly operated by the driver. The traditional mechanical throttle is difficult to achieve the accurate control result. Therefore, the vehicle drivability, fuel economy, and emissions are not satisfactory by using the traditional mechanical throttle. In recent years, new and increasing requirements in terms of emissions control, drivability, and safety have led to the development of electronic throttle system. The electronic throttle is essentially a DC-motor-driven valve that regulates air inflow into the vehicle's combustion system, and the mechanical linkage between accelerator pedal and the throttle is replaced by an electronic connection [13]. Recently, several control strategies for electronic throttle have been presented. In [10], a new intelligent fuzzy controller is proposed. It can handle the nonlinear hysteretic of electronic throttle. In [11], the controller synthesis is performed in discrete time by solving a constrained time-optimal control problem of the throttle. In [12], a robust position controller for motorized throttle body in automotive applications is presented. Complexity of the control problem is explained and control architecture is also presented. In [13], a process to design the control strategy is proposed for a vehicle with the electronic throttle control and the automatic transmission, and the dynamic programming 
(DP) technique is also used to obtain the optimal gear shift and throttle opening angular which maximizes fuel economy while satisfying the power demand. In [14], the nonlinear hysteretic characteristic of the electronic throttle is described and the variable structure control method is proposed to control the electronic throttle. In [15], an adaptive control strategy for the electronic throttle is introduced. In [16], an integrated control strategy is proposed, which consists of a proportional-integral-derivative (PID) controller and a feedback compensator for friction and limp-home effects. In [17], a novel nonlinear controller for the electronic throttle valve is presented, which uses the approximate model method and support vector machine (SVM) modeling. Although the abovementioned control methods can achieve the acceptable control performance, these control methods have complex structure and algorithm. As we know, the controller complex design process often leads to the difficulty of its realization in the actual automotive manufacturing industry. Therefore, more attention has been paid to backstepping design technique because of its systematic design and the excellent transient performance of the closed-loop system. Backstepping design technique is a recursive and systematic design scheme first presented by Kanellakopoulos et al. in 1991 [18]. The main idea is to decompose a complex system into multiple small-scale subsystems, then to design recursively control Lyapunov function and virtual controller for each subsystem, and finally obtain the original control law and realize the global regulation and tracking for the controlled system [1921]. For the systematic design process, backstepping control scheme is easy to be realized, and it has been applied in many cases, such as induction motor [22], chemical process [23, 24], ship course [25], and robot manipulator [26].

Motivated by the advantage of the backstepping design method, this paper investigates the backstepping control problem of the electronic throttle. Since the backstepping design technique is a typical model-based design method, the dynamical model of the electronic throttle is first built in this paper. Based on the proposed dynamical model, the backstepping control design method for the electronic throttle is presented. The proposed backstepping controller can achieve the satisfactory performance; that is, the actual angular of the electronic throttle can track its set point. Finally, a computer simulation is performed, and simulation results verify the effectiveness of the proposed control method.

This paper is organized as follows. Section 2 describes the mathematical model of the electronic throttle. Section 3 designs the electronic throttle controller by using the backstepping method. Section 4 illustrates the simulation results and finally Section 5 shows the conclusion of this paper.

\section{Mathematic Model of the Electronic Throttle}

There are some symbols in this section. At first, definitions of these symbols are described as follows:

$\theta^{*}$ : Set point of the valve plate angular

$\theta(t)$ : Actual angular of the valve plate

$\theta_{0}$ : Static angular of the valve plate $\omega(t)$ : Angular speed of the valve plate

$i_{a}(t)$ : Armature current

$R_{a}:$ Armature resistance

$U_{a}(t)$ : Input voltage of the motor

$U_{b}(t)$ : Electromotive force

$U_{\text {bat }}$ : Supply voltage

$D(t)$ : Duty cycle of the bipolar chopper

$T_{e}(t)$ : Electromagnetism torque

$T_{s}(t)$ : Return spring torque

$T_{f}(t)$ : Friction torque

$K_{t}$ : Torque constant

$K_{s}$ : Elastic coefficient

$K_{m}$ : Torque compensation coefficient

$K_{d}$ : Friction coefficient

$J$ : Moment of inertia

j: Gear ratio.

The schematic of a typical electronic throttle control system is shown in Figure 1.

There are a controller, a bipolar chopper, and an electronic throttle body (ETB) in Figure 1. ETB consists of a DC drive powered by the bipolar chopper, a gearbox, a valve plate, a return spring, and a position sensor. When the valve plate angular is regulated, the air inflow into the vehicle's combustion system can also be regulated. The control objective of the electronic throttle is to control the valve plate angular tracking its set point with the satisfactory performance.

At first, we build the motion equation for the electronic throttle system. The motion equation is

$$
j T_{e}(t)-T_{s}(t)-T_{f}(t)=j^{2} J \frac{d \omega(t)}{d t} .
$$

The relation between current $i_{a}(t)$ and input voltage $U_{a}(t)$ in the armature circuit is described as

$$
i_{a}(t) R_{a}=U_{a}(t)-U_{b}(t),
$$

where

$$
\begin{gathered}
U_{a}(t)=U_{\text {bat }} \times D(t), \\
U_{b}(t)=K_{t} \times j \times \omega(t) .
\end{gathered}
$$

By substituting (3) into (2), we have

$$
i_{a}(t)=\frac{U_{\text {bat }} \times D(t)-K_{t} \times j \times \omega(t)}{R_{a}} .
$$

Computation formula of $T_{e}(t)$ is

$$
T_{e}(t)=K_{t} i_{a}(t) .
$$

By substituting (4) into (5), we get

$$
T_{e}(t)=K_{t} \frac{U_{\text {bat }} \times D(t)-K_{t} \times j \times \omega(t)}{R_{a}} .
$$

Return spring torque $T_{s}(t)$ and friction torque $T_{f}(t)$ are

$$
\begin{gathered}
T_{s}(t)=K_{s}\left(\theta(t)-\theta_{0}\right)+K_{m}, \\
T_{f}(t)=K_{d} \omega(t) .
\end{gathered}
$$




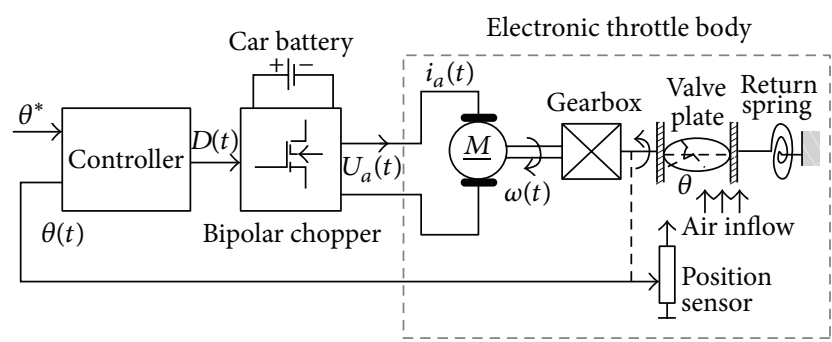

FIGURE 1: Electronic throttle control system.

By substituting (6) and (7) into (1), we get

$$
\begin{aligned}
\frac{d \omega(t)}{d t}= & -\frac{K_{s}}{j^{2} \times J} \times \theta(t)-\left(\frac{K_{t}^{2}}{J R_{a}}+\frac{K_{d}}{j^{2} \times J}\right) \omega(t) \\
& +\frac{K_{t} \times U_{\text {bat }}}{j \times J \times R_{a}} D(t)+\frac{K_{s} \theta_{0}-K_{m}}{j^{2} \times J} .
\end{aligned}
$$

Equation (8) is the mechanism model of the electronic throttle.

Defining state variables $x_{1}(t)=\theta(t), x_{2}(t)=\omega(t)$, input variable $u(t)=D(t)$, and the output variable $y(t)=\theta(t),(8)$ can be rewritten as

$$
\begin{gathered}
\dot{x}_{1}(t)=x_{2}(t), \\
\dot{x}_{2}(t)=-\frac{K_{s}}{j^{2} \times J} \times x_{1}(t)-\left(\frac{K_{t}^{2}}{J R_{a}}+\frac{K_{d}}{j^{2} \times J}\right) x_{2}(t) \\
+\frac{K_{t} \times U_{b a t}}{j \times J \times R_{a}} u(t)+\frac{K_{s} \theta_{0}-K_{m}}{j^{2} \times J} \\
y(t)=x_{1}(t) .
\end{gathered}
$$

Equations (9)-(11) are the state-space model of the electronic throttle.

\section{Backstepping Control Design and Stability Analysis}

The control objective of this paper is to design a backstepping control system such that the output $y(t)$ of the system shown in (11) to track its set point $x_{d}$ asymptotically. The proposed backstepping control procedure is described step by step as follows.

Step 1. For the position-tracking objective, define the tracking error as

$$
z_{1}(t)=x_{1}(t)-x_{d}
$$

Taking $\alpha(t)$ as a virtual control and defining

$$
z_{2}(t)=x_{2}(t)-\alpha(t)
$$

consider the following Lyapunov function candidate:

$$
V_{1}(t)=\frac{1}{2} z_{1}^{2}(t)
$$

The time derivative of $V_{1}(t)$ is

$$
\dot{V}_{1}(t)=z_{1}(t) \dot{z}_{1}(t) .
$$

From (12) and (13), we obtain

$$
\begin{aligned}
\dot{z}_{1}(t) & =\dot{x}_{1}(t) \\
& =x_{2}(t) \\
& =-z_{1}(t)+z_{1}(t)+x_{2}(t)-\alpha(t)+\alpha(t) \\
& =-z_{1}(t)+x_{2}(t)-\alpha(t)+z_{1}(t)+\alpha(t) \\
& =-z_{1}(t)+z_{2}(t)+z_{1}(t)+\alpha(t) .
\end{aligned}
$$

Choosing the virtual control function $\alpha(t)$

$$
\alpha(t)=-z_{1}(t) .
$$

By substituting (17) into (16), we have

$$
\dot{z}_{1}(t)=-z_{1}(t)+z_{2}(t) .
$$

By using (18) and (15), we get

$$
\begin{aligned}
\dot{V}_{1}(t) & =z_{1}(t) \dot{z}_{1}(t) \\
& =z_{1}(t)\left(-z_{1}(t)+z_{2}(t)\right) \\
& =-z_{1}^{2}(t)+z_{1}(t) z_{2}(t) .
\end{aligned}
$$

From (19), we know if $z_{2}(t)$ is equal to zero, the time derivative of $V_{1}(t)$ will be smaller than or equal to zero. If $\dot{V}_{1}(t) \leq 0$, we know that $z_{1}(t)$ will converge to zero, and $x_{1}(t)$ will converge to the set point $x_{d}$. Therefore, in the next step, we will design a controller $u(t)$ to make $z_{2}(t)$ converge to zero.

Step 2. Consider the following Lyapunov function candidate $V_{2}(t)$ :

$$
V_{2}(t)=\frac{1}{2} z_{2}^{2}(t)+V_{1}(t)
$$

The time derivative of $V_{2}(t)$ is

$$
\begin{aligned}
\dot{V}_{2}(t) & =z_{2}(t) \dot{z}_{2}(t)+\dot{V}_{1}(t) \\
& =z_{2}(t) \dot{z}_{2}(t)-z_{1}^{2}(t)+z_{1}(t) z_{2}(t)
\end{aligned}
$$

From (10), (13), and (17), we have

$$
\begin{aligned}
\dot{z}_{2}(t) & =\dot{x}_{2}(t)-\dot{\alpha}(t) \\
& =\mu_{0} u(t)-\mu_{1} x_{1}(t)-\mu_{2} x_{2}(t)+F-\dot{\alpha}(t),
\end{aligned}
$$

where $\mu_{0}=K_{t} /\left(j \times J \times R_{a}\right), \mu_{1}=K_{s} /\left(j^{2} \times J\right)$, and $\mu_{2}=$ $K_{b} \times K_{t} / J R_{a}+K_{d} / j^{2} \times J$ and $F=\left(K_{s} \theta_{0}-K_{m}\right) /\left(j^{2} \times J\right)$.

Note that

$$
\begin{aligned}
\dot{\alpha}(t) & =-\dot{z}_{1}(t) \\
& =-\dot{x}_{1}(t) \\
& =-x_{2}(t) .
\end{aligned}
$$


TABLE 1: Parameter values.

\begin{tabular}{lcr}
\hline$j=20$ & $J=0.02 \mathrm{Kg} \cdot \mathrm{m}^{2}$ & $R=2.1 \Omega$ \\
$K_{b}=0.075 \mathrm{~N} \cdot \mathrm{m} / \mathrm{A}$ & $K_{t}=0.072 \mathrm{~N} \cdot \mathrm{m} / \mathrm{A}$ & $K_{m}=0.34 \mathrm{~N} \cdot \mathrm{m}$ \\
$K_{s}=0.01 \mathrm{~N} \cdot \mathrm{m} / \mathrm{rad}$ & $K_{d}=5 \times 10^{-6} \mathrm{~N} \cdot \mathrm{m} \cdot \mathrm{s} / \mathrm{rad}$ & $\theta_{0}=0.16 \mathrm{rad}$ \\
\hline
\end{tabular}

By substituting (23) into (22), we have

$$
\begin{aligned}
\dot{z}_{2}(t)= & \mu_{0} u(t)-\mu_{1} x_{1}(t)-\mu_{2} x_{2}(t)+F+x_{2}(t) \\
= & \mu_{0} u(t)-\mu_{1}\left[x_{1}(t)-x_{d}+x_{d}\right] \\
& -\mu_{2}\left[x_{2}(t)-\alpha(t)+\alpha(t)\right]+F+x_{2}(t) \\
= & \mu_{0} u(t)-\mu_{1} z_{1}(t)-\mu_{1} x_{d}-\mu_{2} z_{2}(t) \\
& -\mu_{2} \alpha(t)+F+x_{2}(t) \\
= & \mu_{0} u(t)-\mu_{1} z_{1}(t)-\mu_{1} x_{d}-\mu_{2} z_{2}(t) \\
& +\mu_{2} z_{1}(t)+F+x_{2}(t) .
\end{aligned}
$$

Choosing the control function $u(t)$

$$
\begin{array}{r}
u(t)=\frac{1}{\mu_{0}}\left\{\left(\mu_{1}-1\right) z_{1}(t)+\left(\mu_{2}-1\right) z_{2}(t)\right. \\
\left.+\mu_{1} x_{d}-\mu_{2} z_{1}(t)-F-x_{2}(t)\right\} .
\end{array}
$$

From (25) and (24), we have

$$
\dot{z}_{2}(t)=-z_{1}(t)-z_{2}(t)
$$

Substituting (26) into (21) results in

$$
\begin{aligned}
\dot{V}_{2}(t)= & z_{2}(t) \dot{z}_{2}(t)-z_{1}^{2}(t)+z_{1}(t) z_{2}(t) \\
= & z_{2}(t)\left[-z_{1}(t)-z_{2}(t)\right] \\
& -z_{1}^{2}(t)+z_{1}(t) z_{2}(t) \\
= & -z_{1}^{2}(t)-z_{2}^{2}(t) \leq 0 .
\end{aligned}
$$

Equation (27) means that $\dot{V}_{2}(t) \leq 0$. Therefore, it is obtained that the variables $z_{1}(t)$ and $z_{2}(t)$ converge to zero; that is, the output $y(t)=x_{1}(t)$ of the system shown in (11) can track its set point $x_{d}$ asymptotically.

\section{Simulation Experiments}

In this section, we perform simulation experiment to confirm the effectiveness of the proposed backstepping control. The values of the parameters in the electronic throttle system are given in Table 1. All these parameters are obtained from the experiment platform of the electronic throttle in our laboratory.

Simulation results are shown in Figures 2-5. Figure 2 shows the set point of the electronic throttle angular, that is, $x_{d}$. Figure 3 shows the input voltage of the DC servo motor. Figure 4 shows the actual angular of the electronic throttle, that is, $x_{1}(t)$. Figure 5 shows the actual angular speed of the electronic throttle, that is, $x_{2}(t)$. In Figure 2, set point $x_{d}$ is

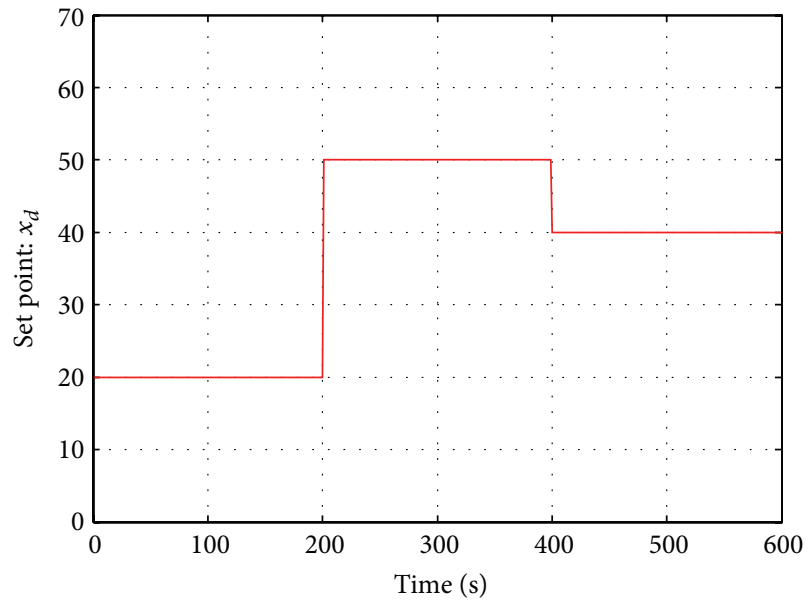

FIGURE 2: Set point of the valve plate angular.

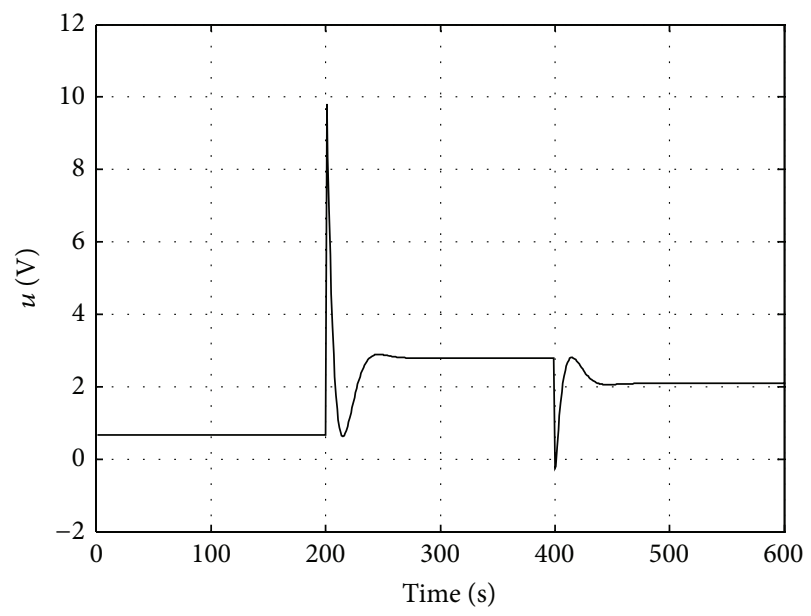

FIGURE 3: Input voltage of the motor.

20 degrees during 0 to 200 seconds. After 200 seconds, $x_{d}$ is increased from 20 to 50 degrees, and after 400 seconds, $x_{d}$ is decreased from 50 to 40 degrees.

At 200 seconds, $x_{d}$ is increased. In order to increase the actual angular $x_{1}(t)$, the input voltage should be increased. From Figure 3, at first, the input voltage is increased when time is 200 seconds. Increase of the input voltage $u(t)$ leads to the increase of the angular speed $x_{2}(t)$, which is shown in Figure 5. When the angular speed $x_{2}(t)$ is increased, the actual angular of the electronic throttle $x_{1}(t)$ will be also increased, which is shown in Figure 4. Therefore, the actual angular $x_{1}(t)$ is regulated to track its set point. When the dynamical regulation process is finished, the input voltage $u(t)$ is a new stable value, and $x_{2}(t)$ is controlled to zero. 


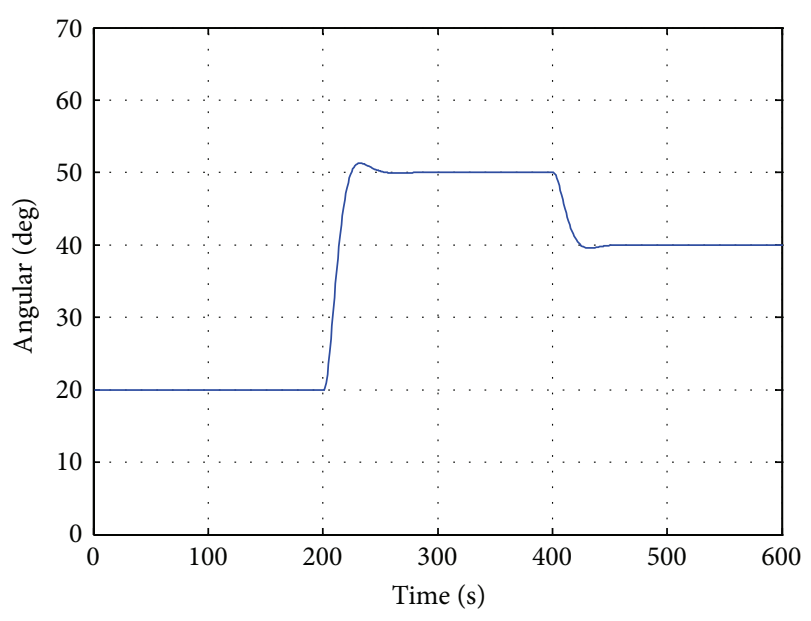

Figure 4: Actual angular of the valve plate.

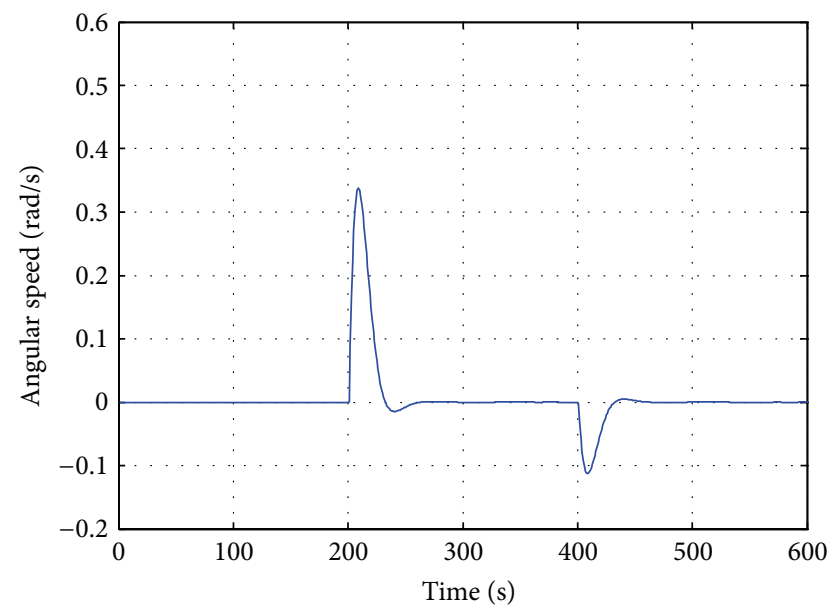

FIGURE 5: Angular speed of the valve plate.

At 400 seconds, $x_{d}$ is decreased. When $x_{d}$ is decreased, in order to decrease the actual angular $x_{1}(t)$, the input voltage should be decreased. From Figure 3, at first, the input voltage is decreased when time is 400 seconds. For the decrease of the input voltage, the angular speed $x_{2}(t)$ is also decreased, which is shown in Figure 5. When the $x_{2}(t)$ is decreased, the actual angular of the electronic throttle $x_{1}(t)$ will be decreased, which is shown in Figure 4. Therefore, the actual angular $x_{1}(t)$ is regulated to track its set point. When the dynamical regulation process is finished, the input voltage is a new stable value, and $x_{2}(t)$ is controlled to zero.

From Figures 2-5, we know that the dynamical process of the simulation experiment is right for the electronic throttle, and the tracking performance is also satisfactory.

\section{Conclusions}

In this paper, the model and control method on the electronic throttle is considered. The dynamical mechanism model and state-space model of the electronic throttle are presented. Based on the state-space model, a backstepping controller is developed. The proposed controller can make the actual angular of the throttle plate track its set point with the satisfactory performance. Simulation experiment is implemented, and the simulation results confirm the effectiveness of the proposed control method.

\section{Conflict of Interests}

None of the authors of the paper has declared any conflict of interests.

\section{Acknowledgments}

This work was supported by the National Natural Science Foundation of China (no. 61074014), Natural Science Fundamental of Liaoning Province (201102089), Program for Liaoning Excellent Talents in University (LJQ2011062), and the State Key Laboratory of Synthetic Automation for Process Industries.

\section{References}

[1] U. Kiencke and L. Nielsen, Automotive Control Systems, Springer, Berlin, Germany, 2005.

[2] S. Yin, S. X. Ding, A. H. A. Sari, and H. Hao, "Data-driven monitoring for stochastic systems and its application on batch process," International Journal of Systems Science, vol. 44, no. 7, pp. 1366-1376, 2013.

[3] Q. Zhou, P. Shi, J. Lu, and S. Xu, "Adaptive output-feedback fuzzy tracking control for a class of nonlinear systems," IEEE Transactions on Fuzzy Systems, vol. 19, no. 5, pp. 972-982, 2011.

[4] Q. Zhou, P. Shi, S. Y. Xu, and H. Y. Li, "Adaptive output feedback control for nonlinear time-delay systems by fuzzy approximation approach," IEEE Transactions on Fuzzy Systems, vol. 21, no. 2, pp. 301-313, 2013.

[5] Q. Zhou, P. Shi, H. H. Liu, and S. Y. Xu, "Neural network based decentralized adaptive output-feedback control for large-scale stochastic nonlinear systems," IEEE Transactions on Systems, Man, and Cybernetics, vol. 42, no. 6, pp. 1608-1619, 2012.

[6] T. Li, W. X. Zheng, and C. Lin, "Delay-slope-dependent stability results of recurrent neural networks," IEEE Transactions on Neural Networks, vol. 22, no. 12, pp. 2138-2143, 2011.

[7] S. Yin, S. Ding, A. Haghani, H. Hao, and P. Zhang, "A comparison study of basic data-driven fault diagnosis and process monitoring methods on the benchmark Tennessee Eastman process," Journal of Process Control, vol. 22, no. 9, pp. 1567-1581, 2012.

[8] H. Li, H. Liu, H. Gao, and P. Shi, "Reliable fuzzy control for active suspension systems with actuator delay and fault," IEEE Transactions on Fuzzy Systems, vol. 20, no. 2, pp. 342-357, 2012.

[9] H. Li, J. Yu, H. Liu, and C. Hilton, "Adaptive sliding mode control for nonlinear active suspension vehicle systems using TS fuzzy approach," IEEE Transactions on Industrial Electronics, vol. 60, no. 8, pp. 3328-3338, 2013.

[10] C. H. Wang and D. Y. Huang, "A New intelligent fuzzy controller for nonlinear hysteretic electronic throttle in modern intelligent automobiles," IEEE Transaction Industrial Electronics, vol. 60, no. 6, pp. 2332-2345, 2013.

[11] M. Vašak, M. Baotić, I. Petrović, and N. Perić, "Hybrid theorybased time-optimal control of an electronic throttle," IEEE Transaction Industrial Electronics, vol. 54, no. 3, pp. 1483-1494, 2008. 
[12] C. Rossi, A. Tilli, and A. Tonielli, "Robust control of a throttle body for drive by wire operation of automotive engines," IEEE Transactions on Control Systems Technology, vol. 8, no. 6, pp. 993-1002, 2000.

[13] D. Kim, H. Peng, S. Bai, and J. M. Maguire, "Control of integrated powertrain with electronic throttle and automatic transmission," IEEE Transactions on Control Systems Technology, vol. 15, no. 3, pp. 474-482, 2007.

[14] Y. Pan, Ü. Özguner, and O. H. Dağci, "Variable-structure control of electronic throttle valve," IEEE Transactions on Industrial Electronics, vol. 55, no. 11, pp. 3899-3907, 2008.

[15] D. Pavković, J. Deur, M. Jansz, and N. Perić, "Adaptive control of automotive electronic throttle," Control Engineering Practice, vol. 14, no. 2, pp. 121-136, 2006.

[16] J. Deur, D. Pavković, N. Perić, M. Jansz, and D. Hrovat, "An electronic throttle control strategy including compensation of friction and limp-home effects," IEEE Transactions on Industry Applications, vol. 40, no. 3, pp. 821-834, 2004.

[17] X. Yuan, Y. Wang, and L. Wu, "SVM-based approximate model control for electronic throttle valve," IEEE Transactions on Vehicular Technology, vol. 57, no. 5, pp. 2747-2756, 2008.

[18] I. Kanellakopoulos, P. V. Kokotović, and A. S. Morse, "Systematic design of adaptive controllers for feedback linearizable systems," Institute of Electrical and Electronics Engineers, vol. 36, no. 11, pp. 1241-1253, 1991.

[19] T. Wang, S. Tong, and Y. Li, "Robust adaptive fuzzy control for nonlinear system with dynamic uncertainties based on backstepping," International Journal of Innovative Computing, Information and Control, vol. 5, no. 9, pp. 2675-2688, 2009.

[20] S.-C. Tong, X.-L. He, and H.-G. Zhang, "A combined backstepping and small-gain approach to robust adaptive fuzzy output feedback control," IEEE Transactions on Fuzzy Systems, vol. 17, no. 5, pp. 1059-1069, 2009.

[21] T. Shaocheng, L. Changying, and L. Yongming, "Fuzzy adaptive observer backstepping control for MIMO nonlinear systems," Fuzzy Sets and Systems, vol. 160, no. 19, pp. 2755-2775, 2009.

[22] F.-J. Lin, C.-K. Chang, and P.-K. Huang, "FPGA-based adaptive backstepping sliding-mode control for linear induction motor drive," IEEE Transactions on Power Electronics, vol. 22, no. 4, pp. 1222-1231, 2007.

[23] B. Chen and X. Liu, "Fuzzy approximate disturbance decoupling of MIMO nonlinear systems by backstepping and application to chemical processes," IEEE Transactions on Fuzzy Systems, vol. 13, no. 6, pp. 832-847, 2005.

[24] D. M. Bošković and M. Krstić, "Backstepping control of chemical tubular reactors," Computers and Chemical Engineering, vol. 26, no. 7-8, pp. 1077-1085, 2002.

[25] A. Witkowska and R. Smierzchalski, "Nonlinear backstepping ship course controller," International Journal of Automation and Computing, vol. 6, no. 3, pp. 277-284, 2009.

[26] Y. Li, S. Tong, and T. Li, "Adaptive fuzzy output feedback control for a single-link flexible robot manipulator driven DC motor via backstepping," Nonlinear Analysis. Real World Applications, vol. 14, no. 1, pp. 483-494, 2013. 


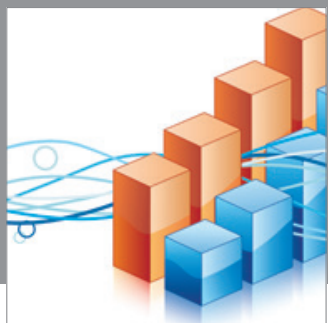

Advances in

Operations Research

mansans

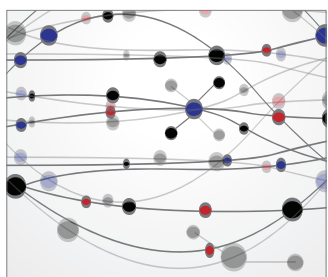

The Scientific World Journal
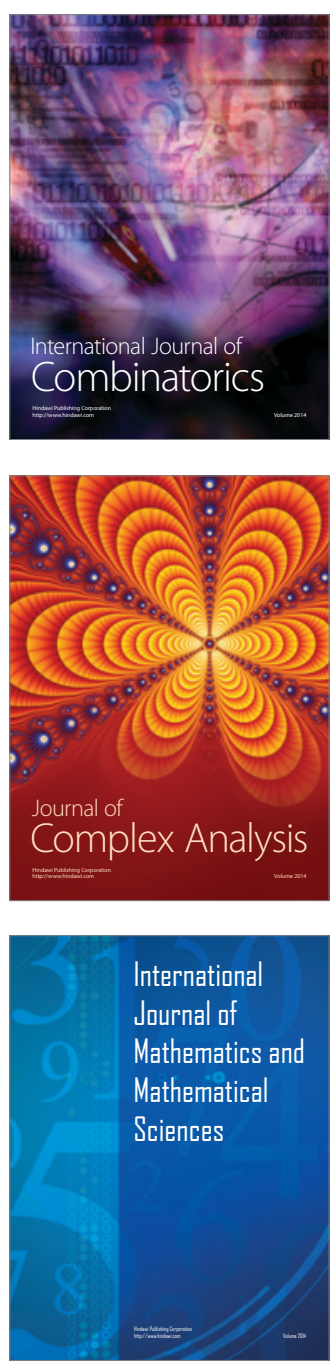
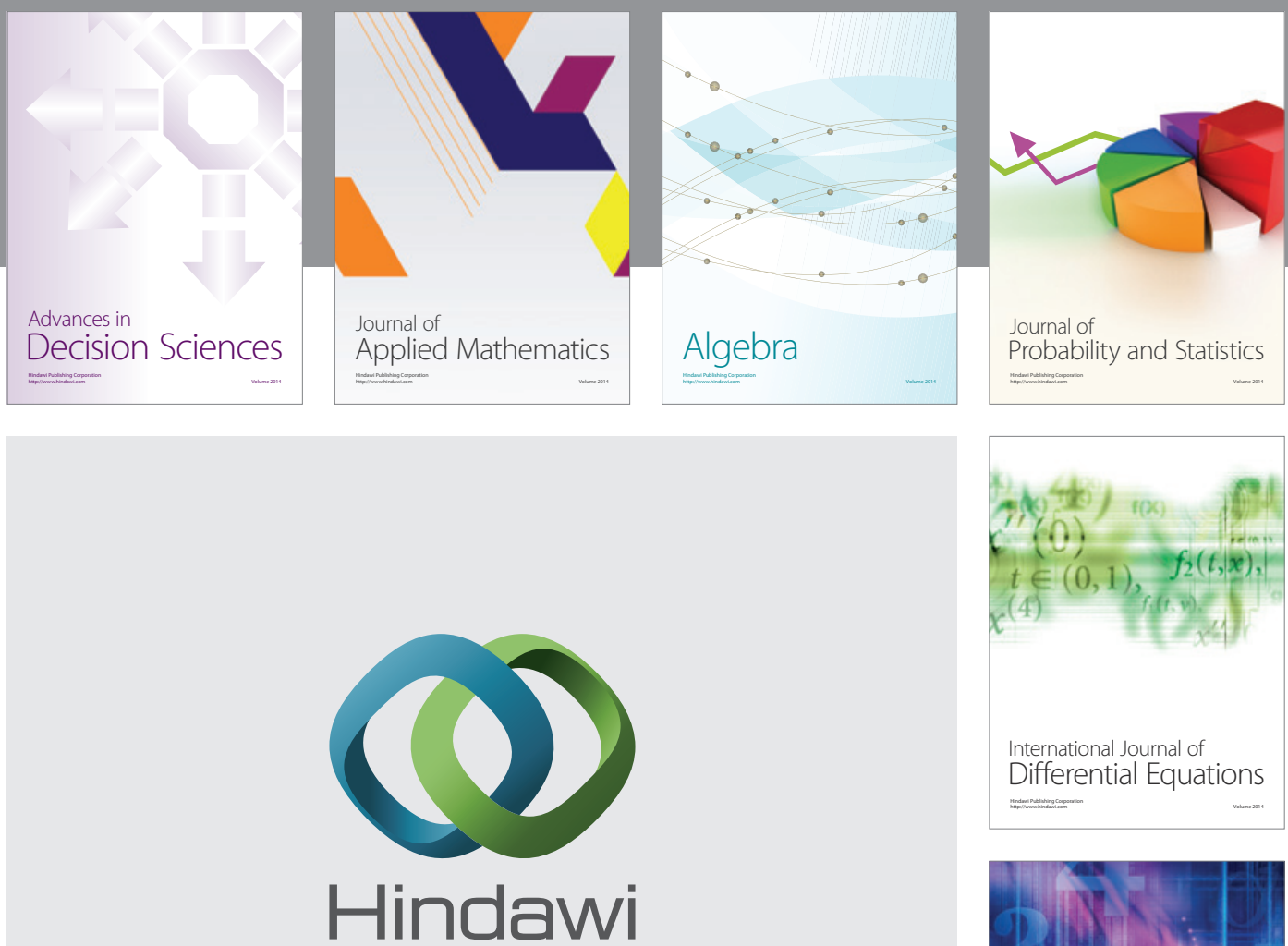

Submit your manuscripts at http://www.hindawi.com
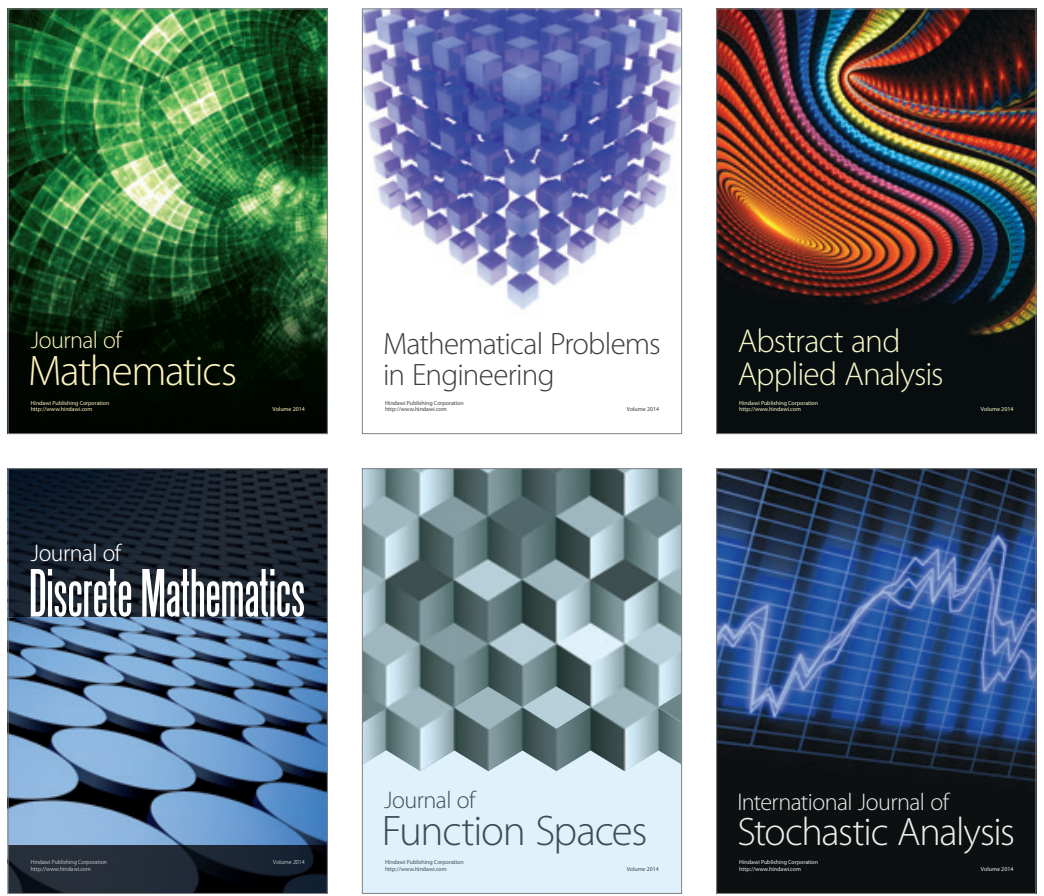

Journal of

Function Spaces

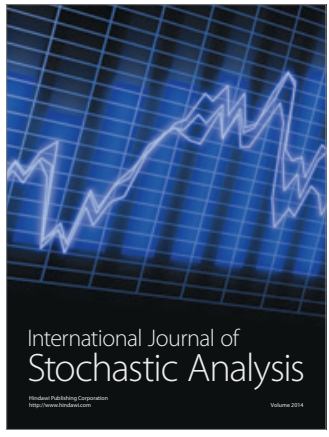

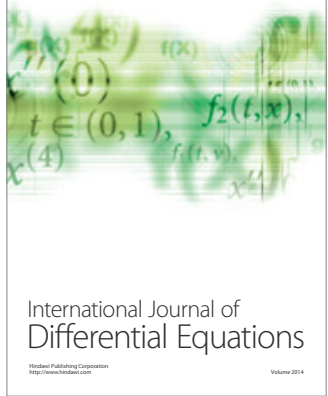
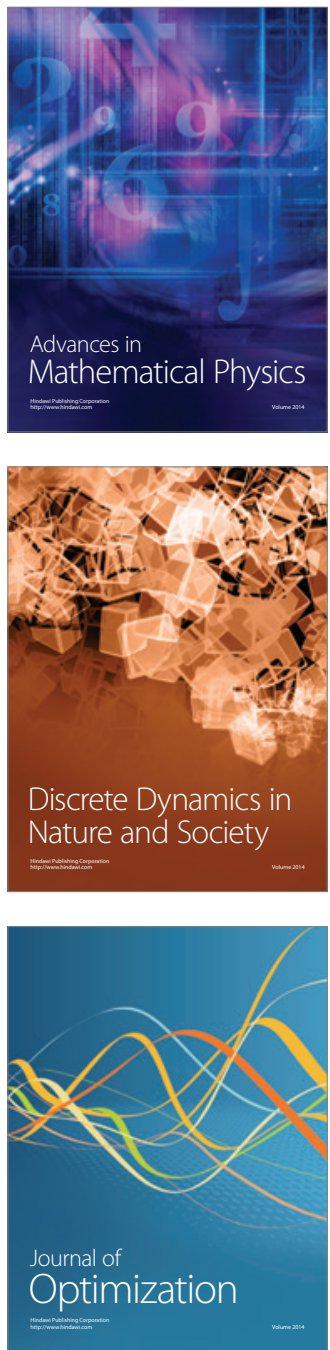